Georgia State University

ScholarWorks @ Georgia State University

Computer Information Systems Faculty

Publications

Department of Computer Information Systems

$9-19-2013$

\title{
Consuming Information Systems: An Economic Model of User Satisfaction
}

Heshan Sun

Clemson University, heshans@clemson.edu

Yulin Fang

City University of Hong Kong, ylfang@cityu.edu.hk

J.J. Po-An Hsieh

Georgia State University, jjhsieh@gsu.edu

Follow this and additional works at: https://scholarworks.gsu.edu/cis_facpub

Part of the Management Information Systems Commons

\section{Recommended Citation}

Sun, Heshan; Fang, Yulin; and Hsieh, J.J. Po-An, "Consuming Information Systems: An Economic Model of User Satisfaction" (2013). Computer Information Systems Faculty Publications. 33.

https://scholarworks.gsu.edu/cis_facpub/33

This Article is brought to you for free and open access by the Department of Computer Information Systems at ScholarWorks @ Georgia State University. It has been accepted for inclusion in Computer Information Systems Faculty Publications by an authorized administrator of ScholarWorks @ Georgia State University. For more information, please contact scholarworks@gsu.edu. 


\title{
Consuming Information Systems: An Economic Model of User Satisfaction
}

Published at Decision Support Systems 2014

\author{
Heshan Sun \\ (Corresponding Author) \\ Assistant Professor \\ Management Department, Clemson University \\ 107 Sirrine Hall \\ Clemson University \\ Clemson, SC 29630 \\ Tel: +1 (864)656-0628 \\ heshans@clemson.edu
}

\author{
Yulin Fang \\ Associate Professor \\ Department of Information Systems, College of Business \\ City University of Hong Kong \\ P7722, Academic Building, City University of Hong Kong \\ 83 Tat Chee Avenue, Kowloon Tong, Hong Kong \\ Tel: +85234427492 \\ ylfang@cityu.edu.hk
}

\author{
J.J. Hsieh \\ Associate Professor \\ Deputy Direct of Doctor of Management Program \\ Department of Management and Marketing, Faculty of Business \\ Hong Kong Polytechnic University \\ JJ.Hsieh@inet.polyu.edu.hk
}




\begin{abstract}
This paper has two major objectives. The first objective intends to answer the following question which is of significant interest to information system (IS) researchers and practitioners: How does user satisfaction (satisfaction) respond to changes in system use and system attributes? The second and more ambitious objective is to promote the application of economic theories in user behavior research. In contrast to prior research that conceived the development of user satisfaction as an information valuation and integration process, we consider such development to be embedded in the IS consumption process, that is, users gain utility (satisfaction) from consuming (using) the system. This perspective enables us to re-conceptualize user satisfaction as a proxy of utility and apply utility research in economics to study user satisfaction. An economic model of user satisfaction was developed. Two empirical studies were conducted to examine the research model. The findings confirmed the consumptive nature of user satisfaction. Apart from enriching our understanding of user satisfaction, this research demonstrates the usefulness of economic theories in user behavior research.
\end{abstract}

Keywords: User satisfaction, marginal utility, information quality, economic theory, information technology consumption 


\section{Introduction}

As a major intervener between information technology (IT) investments and the realization of their economic value, user satisfaction (satisfaction) has been an enduring topic of interest over the past two decades $[6,37,67]$. This paper attempts to answer the following important yet under-researched question: How does user satisfaction respond to changes in system use and to system attributes? IT practitioners often attempt to promote the use and quality of information systems (ISs), thus they need to know how such efforts work to improve user satisfaction. Understanding this research question helps practitioners formulate an optimal IS implementation strategy and make better decisions regarding resource allocation to maximize user satisfaction.

Among various theoretical lenses applied by scholars to investigate IS user satisfaction, the IS Success Model by DeLone and McLean [19] continues to be widely used. Relying strongly on information integration theory (IIT) in psychology [4, 24], the IS Success Model and its subsequent extensions have predominantly focused on how users evaluate information systems and integrate their evaluations in developing user satisfaction. Linear models have been widely used in user satisfaction studies, indicating the presumed monotone effect of system use and user perceptions of system attributes (such as information quality and system quality) on user satisfaction. Our specific research question -i.e., how user satisfaction responds to changes (increases or decreases) in system use and to improvements or deteriorations in system attributes - remains unanswered.

Several studies have explored the non-linear formation of user satisfaction from different theoretical perspectives. Drawing on the lens of information integration, Sethi and King [68] examined whether different ways (linear and non-linear) of integrating cognitive elements affect user satisfaction. However, the results of their study offer minimal insights to explain the effects of changes in the perception of system attributes on user satisfaction. Grounded on expectation-disconfirmation theory in psychology, Brown et al. [14] applied polynomial regression analysis to investigate whether non-linear relationships exist across experience, expectation, and user satisfaction. They argued that researchers' use 
of polynomial analysis is consistent with expectation-disconfirmation theory; however, their results suggest that the investigated relationships are linear in nature. The aforementioned studies, all inspired by psychological theories, investigate possible non-linear relationships across user evaluation, user experience, and user satisfaction. However, none of these studies have theoretically modeled how user satisfaction responds to changes in user evaluations and system use.

To achieve this end, this research refers to economics for theoretical support. Economics, especially microeconomics, explicitly studies changes in user utility and preferences, and thus can be helpful in exploring the answer to our research question. Conceiving user satisfaction as a proxy of the utility derived from IS consumption, we draw on utility research to re-theorize the relationships between user satisfaction and system use and between user satisfaction and information quality/system quality. Specifically, we use Law of Diminishing Marginal Utility to propose non-linear effects from system user and information and system qualities on user satisfaction. Accordingly, the more a person uses an IS, the less an increase in system use will enhance user satisfaction. Similarly, the higher the information quality/system quality is, the less one unit change in information quality/system quality can contribute to user satisfaction.

This paper makes two primary contributions. First, this research is the first to offer an enriched understanding of user satisfaction by referring to economics as the theoretical foundation. As will be illustrated in detail later, this paper uses Utility Theory in economics to re-conceptualize user satisfaction and its relationship with information quality, system quality, and system use, thereby advancing our understanding of the nature of user satisfaction. This also renders significant practical implications with regard investment on information systems improvement, as will be discussed later. Second, this paper bridges economic research and user behavior research. "We see things in part by how we talk about them and the concepts and constructs we use in our descriptions" [23, p. 16]. This research demonstrates how to apply the utility theory to study user satisfaction with information systems. To do so, several assumptions held in economics are released. We hope that this research can encourage more studies in the interdisciplinary area of economics and user behavior. 


\section{Conceptual Developments}

\subsection{Theoretical Foundation: Utility Theory}

Utility is a fundamental concept in economics. Its definition has changed over the past centuries. The original definition of utility dates back to the 1780 s. Bentham conceived utility as "pleasure and pain, the 'sovereign masters' that 'point out what we ought to do, as well as determine what we should do"' [10, cited from 41]. This original definition views utility as a subjective feeling. Conceptually, utility is abstract rather than concrete or observable. We can arbitrarily assign a value to measure utility for the sake of comparison (for example, we can compare apples and bananas in terms of how much utility a person can obtain from eating them). As the foundation of classical economics, the work of Bentham profoundly influenced economists during his time and in the succeeding generations [21, 39]. Bentham's definition of utility was later labeled as experienced utility because it emphasized the actual experience of people [41]. Subsequent researchers also proposed other types of utilities, e.g., decision utility (utility that can be inferred from decisions) $[65,75,76]$. Nevertheless, the definition of Bentham is the most fundamental and hence, the most widely used. In fact, Kahneman et al. [41] emphasized that we should "go back to Bentham" when studying utility. Accordingly, we refer to the traditional Bentham definition of utility in this research.

A revolutionary event in the field of economics was the development of the notion of marginal utility by neoclassical economists $[39,49,53]$. In contrast to preceding classical economics movement that focused on total utility, neoclassical economics emphasized marginal utility. Marginal utility refers to the additional benefit or amount of utility gained from each extra unit of consumption. According to the law of diminishing marginal utility, marginal utility decreases with each additional unit of increase in the consumption of a good (Figure 1). Marginal utility depends on how much a person has already consumed, such that the more goods an individual consumes, the less incremental utility he or she obtains from the last unit of that good. Accordingly, total utility increases at a slower pace as an individual consumes more 
of the same good (for example, a person obtains less utility from the second apple than from the first one). With few exceptions, goods exhibit diminishing marginal utility [31].

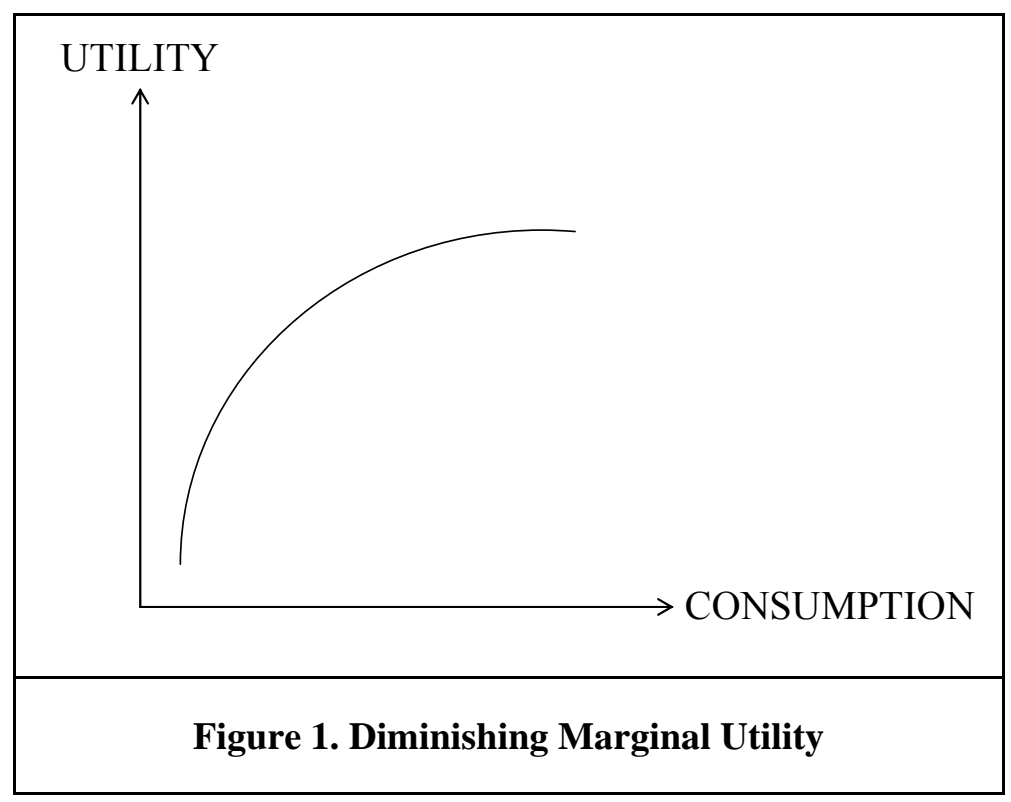

Bentham's definition of utility focuses on past consumption, whereas the other stream of utility research emphasizes expected utility of future consumptions. Researchers [e.g., 5, 26, 43, 66, 93] have argued that a person chooses between prospects by comparing their expected utility values. Specifically, expected utility values of prospects are usually conceived as the weight sums obtained by adding utility values of outcomes multiplied by their respective probabilities. People compare utilities of the future state with the current state. Rational people would wish to obey the axioms of the theory, and most people do so most of the time [40].

Furthermore, when developing their Nobel Prize-winning prospect theory, Kahneman and Tversky $[40,86]$ argued that people evaluate utility of prospects based on gains and losses relative to a reference point rather than on weight sums of the utility of different outcomes [9]. A reference point is usually the "current position" of an individual, although exceptions exist $[9,86]$. For example, a widely used reference point in economics is current wealth. The impact of a prospect of wealth on a person's happiness depends on the amount of wealth he/she currently possesses. 
Despite its differences from the original utility theory, the prospect theory also embraces diminishing sensitivity ${ }^{1}$, a concept similar to the law of diminishing marginal utility. Diminishing sensitivity posits that the first expected gains/losses lead to the largest increase/decrease in utility [9, 40, 86]. The value of a change (that is, marginal value) "decreases with the distance from the reference point" [86, p.1048]. Although diminishing sensitivity and diminishing marginal utility are "logically independent" [86, p.1049], both predict that the distance from the current status determines incremental contribution to utility of one unit change of consumption/evaluations. From the reference point (the current status), additional consumption contributes diminishingly to utility. Therefore, both utility theory and prospect theory will yield an empirically similar diminishing contribution of deviations from the reference point.

\subsection{Re-theorization of the IS Success Model: A Utility Approach}

Although prior IS Success studies have resulted in various model re-specifications and extensions $[20,63,67]$, user satisfaction remains a pivotal construct. Satisfaction has been conceptualized as "a subjective evaluation of the various consequences... evaluated on a pleasant-unpleasant continuum" [67, p.246]. Satisfaction has also been viewed as "the attitude that a user has toward an information system" [97 p. 87], an object-based attitudinal evaluation of the system rather than the use of the system alone. From the utility perspective, we conceive user satisfaction, which has an obvious happiness component in its definition, as a valid proxy for utility. As stated earlier, utility refers to the subjective pleasure and pain of a person and cannot be measured directly [10, cited from 41]. A number of experts describe utility as "agreeable states of consciousness," whereas others explicitly refer to utility as "the satisfaction of people's informed preferences or desires" [31 p.243]. Therefore, definitions of utility in economics are consistent with the traditional definition of user satisfaction in IS research. Indeed,

\footnotetext{
${ }^{1}$ One major assumption of the prospect theory is that people are generally risk averse $[40,80,85]$ and as such, people usually place more weight on potential losses than potential gains. However, we do not study risk aversion in this paper, that is, we do not distinguish between the weights of gains and losses because of two reasons. First, both gains and losses still demonstrate diminishing sensitivity; from a reference point, marginal sensitivity of both gains and losses is declining. Second, expected utility theory has long considered risk aversion to be equivalent to the concavity of the utility function, that is, diminishing marginal utility $[5,62]$. Nevertheless, risk aversion is a promising topic for future research.
} 
satisfaction has been conceived as experienced utility and is related to "happiness." [15, 41]. Therefore, it is legitimate to conceive satisfaction as an indicator/proxy of utility.

It is worth noting that the utility theory has been applied, extended, and appropriated in other disciplines, as what this research attempts to do with regard to user satisfaction. This is often done by releasing assumptions held in economics in several ways. First, the dependent variable is not limited to the originally defined utility. The original definition of utility is primarily about subjective "happiness." Researchers in other disciplines have extended this by applying utility theory to study other dependent variables such as customer satisfaction [54], perceived product similarity [27], consumer product adoption [56], and willingness to pay [34], arguing that the law of diminishing utility is not limited to subjective feeling of happiness. Similarly, this research applies utility theory to study user satisfaction with information systems.

Second, extending the original utility theory, researchers have studied the relationship between consumptions of different "goods." The original utility theory has traditionally been focused on singular products or services. This has been expended to study consumptions of different attributes of a product or service. For example, to study the impact of new product attributes, Nowlis and Simonson [56] proved that the addition of a new feature contributes more value to a relatively inferior product than to a superior one, referring to the "common assumption in economics that value function are concave." (p. 37). More explicitly, the utility of a new feature is dependent on the utility of the different features already included in the product/service. Similarly, referring to the diminishing marginal utility, Mittal et al. [54] showed that improvement of attribute (i.e., feature) -level performance has diminishing impact on consumer satisfaction. In both studies, the impact on satisfaction from the improvement in one attribute on the product that includes a large number of other attributes still follows the law of diminishing marginal utility.

Third, while the original utility theory treats the consumer as a "sovereign master," implying that consumption is completely voluntary, people can still derive utility, i.e., satisfaction, from mandated consumption. For example, Brown $[13,14]$ argued that in mandatory use contexts, as "employees must 
use the system to perform their job functions, there are no alternatives to actual use," (p. 233) user satisfaction, relative to IS use, is a more appropriate indicator of IS success. Hsieh et al. [35] made a similar argument that user satisfaction is indeed a better indicator than system use in mandatory use contexts. Chan et al. [16] also showed that people can form satisfaction with mandated e-government systems. The rationale is that even when use is mandatory people still vary in the quality and intensity of use [32]. After all, as indicated by DeLone and McLean, "no system use is totally mandatory" [20, p. 16].

In addition, it is likely that the influence of voluntariness/mandatoriness is limited only to the early stage — rather than the later stage — of system implementation. For example, Venkatesh and colleagues [92] showed that there is a direct influence of social influence on using a technology in mandatory contexts, but not in voluntary context. However, this difference is limited to the early stage of system implementation. At the later stage of system implementation, the direct influence of social influence on system use disappears in both voluntary and mandate contexts.

A strong advantage of conceiving user satisfaction as utility is found in the law of diminishing marginal utility. It has been known that system use contributes positively to job performance and user satisfaction $[19,20,83,84]$. System use indicates how much the user exploits the system to enhance task performance and thus can be an indicator of how much the user "consumes" the information system. The more a person uses a system, the more he/she experiences and exploits capacity of this system.

This research posits that the impact of system use on user satisfaction also complies with the law of diminishing marginal utility, assuming that information systems are normal goods. That is, the incremental contribution of an increase in system use constantly decreases when people use a system more frequently. The learning effect can help explain the diminishing utility of system use. Specifically, people know a limited number of system features when first interacting with the system. Over time, they learn more about how to use the system. They may learn more features or new ways of using the system [78]. This is often done in cycles of adaptation: that is, the users learn new things about using the system, followed by another cycle of learning $[38,46]$. Such learning effect, however, is more salient at the 
beginning when the system is unknown to the users and when there are windows of opportunities to explore it [88]. The opportunities to learn new things about the system become scarcer over time when the unknown features are fewer. In order words, the learning effect of system use on user satisfaction, if any, diminishes over time. In summary, the law of diminishing marginal utility of system use suggests that the current amount of system use determines to what degree an increase in system use contributes to enhancing user satisfaction.

\section{Hypothesis 1: System use demonstrates diminishing impact on user satisfaction such that system use has less impact on user satisfaction when the system is used more frequently.}

The IS Success Model attributes the development of user satisfaction to two user perceptions: information quality and system quality $[19]^{2}$. Information quality refers to user perception of the quality of system output and has also been labeled as data quality [98]. It is conceived as the semantic success of an information system and relates to features such as information completeness, accuracy, format, currency, relevance, timeliness, precision, reliability, and conciseness [63, 68, 81]. System quality, on the other hand, is more concerned with the technical success of an IS (DeLone and McLean, 1992), such as system reliability, flexibility, integration, error recovery, accessibility, language, and timeliness $[19,36$, 97].

The utility research suggests a non-linear influence of information and system qualities on user satisfaction. The rationale is that people "consume" information and system attributes. As stated earlier, people evaluate changes of future prospects in reference to the current status. We generalize this logic to evaluations of changes of information quality/system quality. Accordingly, the impact on user satisfaction of a potential change in information quality/system quality depends on the current level of quality. When

\footnotetext{
${ }^{2}$ DeLone and McLean (2003) modified the IS Success Model by adding IS service quality as a new antecedent of user satisfaction. However, as they pointed out, "To measure the success of a single system, 'information quality' or 'system quality' may be the most important quality component. For measuring the overall success of the IS department, as opposed to individual systems, 'service quality' may become the most important variable. Once again, context should dictate the appropriate specification and application of DeLone and McLean's IS Success Model” (page 18). Given our focus on user satisfaction with a specific IS rather than an IS department, IS service quality may not be a critical antecedent for user satisfaction. This paper, therefore, does not include service quality in the model.
} 
the current level of information quality/system quality is already high, an increase of this quality will result in less increase in utility. Conversely, when the current level of information quality/system quality is low, a unit of improvement in this quality is more conspicuous and accordingly generates a larger impact on overall satisfaction.

A case in point is Amazon.com. When it was first launched in 1995 as an online bookstore, the inclusion of a new product line (such as toys), which can be viewed as a change in information completeness of Amazon.com, was significant news. The news attracted many new customers and was found to enhance customer satisfaction greatly. Today, adding a new product line in Amazon.com is unlikely to stimulate a similar level of impact because consumers already have access to many product lines in Amazon.com. Because Amazon.com has already obtained a high level of information quality, a new addition is less likely to create a significant increase in customer satisfaction.

Marketing research also supports the importance of contrast between a new product feature and existing features $[28,56]$. Evaluation of a newly added feature is affected by whether this feature is assimilated by or contrasted against the overall value of the brand to which it is added, resulting in the diminishing utility of the new feature $[28,56]$. When a product is of high quality (for example, it has superior features or it belongs to a popular brand name), a new feature is assimilated into the existing perception of high quality of the product, thus the new feature is unlikely to create a significant influence. Conversely, the addition of a new feature to an otherwise inferior product is likely to create a contrasting effect, thus leading to a relatively large impact on overall product evaluation [27, 56, 74]. In summary, the marginal utility of a particular dimension is declining as the magnitude of the dimension increases [82]. Information quality/system quality can also deteriorate because people may perceive quality as being lower than before. In such cases, the aforementioned argument is still valid. It is necessary at this point to bring in the notion of multi-attribute utility, an important extension to the original utility theory. The notion of multi-attribute utility is of particular merit to this study in light of the fact that an information system is often complex and consists of multiple features (i.e., attributes). As mentioned earlier, a person often evaluates the utility of a new feature based on the utility of existing features [56]. 
The rationale is that the contrast between the new feature and the existing features matters so that the larger the contrast, the greater the influence of the new feature on the user's evaluation. Hence, when the current level of information quality/system quality is high, a unit of deterioration of this quality is salient by contrast and significantly lowers user satisfaction. Conversely, when the current level of information quality/system quality is already low, a unit of deterioration of this quality is less salient and contributes less to lowering user satisfaction.

In summary, the current level of information quality/system quality serves as the reference point and determines the degree achieved by the improvement/deterioration of this quality and contributes to the enhancement of user satisfaction.

Hypothesis 2: Information quality demonstrates diminishing influence on user satisfaction such that information quality has less impact on user satisfaction when information quality increases.

Hypothesis 3: System quality demonstrates diminishing influence on user satisfaction such that system quality has less impact on user satisfaction when system quality increases.

\section{Empirical Studies}

We conducted two longitudinal field studies under different contexts for hypothesis testing (that is, for the generalizability of the hypotheses). Study 1 surveyed 195 users of a service IS (SIS) in the call center of a large service firm in China, representing a mandatory-use context. Study 2 investigated the use of a wiki system by 84 Master students, representing a voluntary-use context.

\subsection{Study One: Service Information Systems}

The first study was conducted in a call center of a large service company in China. Customer service representatives (CSRs) use the SIS of the firm to respond to customer inquiries via telephone. Similar to most SISs [69], this system contains sophisticated information about regular and promotional products, service offerings, company policies, and all customer-related information, such as customer 
profiles, billing histories, and preferences. This SIS enables CSRs to increase customer value by identifying add-ons or cross-selling opportunities. Similar to most initiatives that deploy SISs to support frontline CSR operations, the subjects are required to use the system in their daily work [51]. By the time we collected our data, the system had been in place for 16 months and was being routinely operated.

Data collection process involved several steps. First, two certified translators performed standard instrument translation and back-translation between English and Chinese [12]. We then conducted a pilot study to examine construct validity and reliability using 31 CSRs who used the target system in daily operation. Minor revisions were made according to subject feedback.

This study included two waves of examinations, with the first wave measuring the independent variables (IVs) (information quality, system quality, and use), the dependent variable (DV) (satisfaction), and the control variables. The second wave measured only the IVs and DV. At Time 1 (T1), the instrument was distributed to 300 CSRs randomly sampled from the call center, and 250 responded. We contacted the same 250 respondents six months later (T2), and 195 responded. Similar to the findings in prior call center studies $[48,69]$, CSR subjects were more likely to be female and have an educational level lower than a bachelor's degree (Table 1). Collecting data at two time points enables us to assess if our findings at T1 are reliable over time (i.e., at T2) at the same research site. Study 1 enabled collection of data at two points. We thus leveraged this opportunity and proved that our findings are stable.

\begin{tabular}{|c|c|c|}
\hline \multicolumn{3}{|c|}{ Table 1. Sample demographics of Study 1 } \\
\hline \multirow{2}{*}{ Education } & Category & Percentage \\
\hline & Senior high school & $38.5 \%$ \\
\cline { 2 - 3 } & College (Associate Degree) & $59.0 \%$ \\
\cline { 2 - 3 } & Bachelor's or higher & $2.6 \%$ \\
\hline \multirow{2}{*}{ Gender } & Male & $5.6 \%$ \\
\hline & Female & $94.4 \%$ \\
\hline & Mean & Std. deviation \\
\hline Age (year) & 23.22 & 3.09 \\
\hline Prior experience with the system (month) & 13.93 & 4.61 \\
\hline Prior customer service experience (month) & 22.06 & 12.39 \\
\hline
\end{tabular}




\section{Measures}

The measures can be seen in Appendix A. Whenever possible, we adapted previously validated measures with minor modifications tailored for our specific areas of inquiry. Three items each for both information quality and system quality were adapted from the research of Wixom and Todd [97]. As SIS use by the CSRs is mandatory, we measured CSR system use by asking the subjects to specify the percentage of their work time using the SIS by using a 0-100\% scale [63]. Marketing scholars have measured consumer satisfaction using various types of scales, including multi-item Likert scales, 0 to 100 ratio scales, or facial/graphical expressions [33]. We adopted the single-item 0 to 100 ratio scale $[59,96]$ to measure user satisfaction in order to minimize the common scale format bias cautioned by Padsokoff et al. [60] and Sharma et al. [71]. We also controlled for factors that might affect individual responses to IS, including gender, age, and prior experience on the technology being investigated to safeguard against alternative explanations.

\section{Algorithm}

We developed a quadratic regression equation (QRE) to model the non-linear relationship between user satisfaction and the predictors (information quality, system quality, and Use). The QRE is a widely used approach in economics for modeling marginal utility $[40,64,86]$. In addition, this strategy is consistent with prior research that applied the utility theory to study satisfaction [e.g., 54]. This non-linear approach can circumvent several methodological shortcomings arising from the linear scheme [22, 47, 58]. The satisfaction model is depicted as follows:

$$
\begin{gathered}
\text { Sat }=\beta_{0}+\beta_{1} \text { Info } Q+\beta_{2} \text { Sys } Q+\beta_{3} \text { Use }+\beta_{4} \text { Info } Q^{2}+\beta_{5} \text { Sys }^{2}+\beta_{6} U s e^{2} \\
\left(\beta_{0}, \beta_{1}, \beta_{2}, \beta_{3}>0 ; \beta_{4}, \beta_{5}, \beta_{6}<0\right)
\end{gathered}
$$

\section{Measurement Model}

Given the available sample size, confirmatory factor analysis (CFA) using AMOS 6.0, a more conservative technique, was performed to assess the psychometric properties of the two multi-item 
constructs (information quality and system quality) at both $\mathrm{T} 1$ and $\mathrm{T} 2$. CFA results indicate that all indices were higher than the criterion levels (Table 2). In terms of reliability, the values of Cronbach's alpha and composite reliability were all greater than 0.707 (Tables 3 and 4) [57]. The average variance extracted (AVE) for each construct was higher than 0.50 (Tables 3 and 4), suggesting that the observed items show more variance than the error terms [25]. Items loaded heavily on their constructs (Table 5).

As for common method bias (CMB), the instruments contained different scale formats in order to reduce scale commonality [71]. We also performed the Harmon one-factor test, as recommended by Podsakoff et al. [60]. A factor analysis combining the IVs and DV revealed no signs of a single factor accounting for the majority of the covariance, indicating that CMB is not a concern.

\begin{tabular}{|c|c|c|c|}
\hline \multicolumn{5}{|c|}{ Table 2. Fit indices of CFA (Study 1) } \\
\hline $\begin{array}{c}\text { Fit } \\
\text { indices }\end{array}$ & $\begin{array}{c}\text { Measurement model } \\
\text { (Time 1) }\end{array}$ & $\begin{array}{c}\text { Measurement model } \\
\text { (Time 2) }\end{array}$ & $\begin{array}{c}\text { Desired } \\
\text { levels }\end{array}$ \\
\hline$\chi^{2} / \mathrm{df}$ & 1.92 & 1.47 & $<3.0$ \\
\hline CFI & 0.99 & 0.99 & $>0.90$ \\
\hline TLI & 0.99 & 0.99 & $>0.90$ \\
\hline GFI & 0.98 & 0.98 & $>0.90$ \\
\hline AGFI & 0.94 & 0.95 & $>0.80$ \\
\hline RMSEA & 0.07 & 0.05 & $0.05-0.08$ \\
\hline Standardized RMR & 0.03 & 0.01 & $<0.08$ \\
\hline
\end{tabular}

Table 3. Descriptive, internal consistency, convergent, and discriminant validity (Study 1, Time 1)

\begin{tabular}{|c|c|c|c|c|c|c|c|c|c|}
\hline Constructs & Mean & $\begin{array}{l}\text { Standard } \\
\text { deviation }\end{array}$ & $\begin{array}{c}\text { Cronbach's } \\
\text { Alpha }\end{array}$ & $\begin{array}{l}\text { Composite } \\
\text { reliability }\end{array}$ & AVE & 1 & 2 & 3 & 4 \\
\hline 1. Information quality & 4.10 & 1.20 & 0.92 & 0.94 & 0.81 & $0.90(a)$ & & & \\
\hline 2. System quality & 3.66 & 1.28 & 0.93 & 0.95 & 0.85 & $0.65(b)$ & 0.92 & & \\
\hline 3. Use (d) & 0.76 & 0.18 & N/A & N/A & N/A & 0.20 & 0.15 & N/A & \\
\hline 4. User satisfaction $(\mathrm{d})$ & 0.53 & 0.17 & N/A & N/A & $\mathrm{N} / \mathrm{A}$ & 0.57 & 0.64 & 0.12 & N/A \\
\hline \multicolumn{10}{|c|}{$\begin{array}{l}\text { a. Diagonals represent the square root of the average variance extracted (AVE). } \\
\text { b. Off diagonal elements are the correlations among constructs. } \\
\text { c. For discriminant validity, diagonal elements should be larger than off-diagonal elements. } \\
\text { d. A single-item measure was used. }\end{array}$} \\
\hline
\end{tabular}


Table 4. Descriptive, internal consistency, convergent, and discriminant validity (Study 1, Time 2)

\begin{tabular}{|l|c|c|c|c|c|c|c|c|c|}
\hline \multicolumn{1}{|c|}{ Constructs } & Mean & $\begin{array}{c}\text { Standard } \\
\text { deviation }\end{array}$ & $\begin{array}{c}\text { Cronbach's } \\
\text { Alpha }\end{array}$ & $\begin{array}{c}\text { Composite } \\
\text { reliability }\end{array}$ & $\mathbf{A V E}$ & $\mathbf{1}$ & $\mathbf{2}$ & $\mathbf{3}$ & $\mathbf{4}$ \\
\hline $\begin{array}{l}\text { 1.Information } \\
\text { quality }\end{array}$ & 4.35 & 1.34 & 0.96 & 0.89 & 0.86 & $\mathbf{0 . 9 3 ( a )}$ & & & \\
\hline 2. System quality & 3.96 & 1.36 & 0.96 & 0.96 & 0.88 & $0.68(\mathrm{~b})$ & $\mathbf{0 . 9 4}$ & & \\
\hline 3. Use (d) & 0.78 & 0.18 & N/A & N/A & N/A & 0.32 & 0.21 & N/A & \\
\hline $\begin{array}{l}\text { 4.User satisfaction } \\
\text { (d) }\end{array}$ & 0.56 & 0.19 & N/A & N/A & N/A & 0.65 & 0.66 & 0.25 & N/A \\
\hline
\end{tabular}

a. Diagonals represent the square root of the AVE.

b. Off diagonal elements are the correlations among constructs.

c. For discriminant validity, diagonal elements should be larger than off-diagonal elements.

d. A single-item measure was used.

\begin{tabular}{|c|c|c|c|}
\hline \multicolumn{4}{|c|}{ Table 5. Item loadings (Study 1) } \\
\hline Construct & Items & Time 1 & Time 2 \\
\hline \multirow{3}{*}{ 1. Information quality } & InfoQ1 & 0.909 & 0.954 \\
\cline { 2 - 4 } & InfoQ2 & 0.953 & 0.947 \\
\cline { 2 - 4 } & InfoQ3 & 0.900 & 0.921 \\
\hline \multirow{3}{*}{ 2. System quality } & SysQ1 & 0.927 & 0.947 \\
\cline { 2 - 4 } & SysQ2 & 0.933 & 0.968 \\
\cline { 2 - 4 } & SysQ3 & 0.908 & 0.913 \\
\hline
\end{tabular}

\section{Structural Model}

We used hierarchical regression analysis (HRA) via the software SPSS 19.0 for hypothesis testing of the data. HRA is considered more appropriate compared with structural equation modeling techniques, such as partial least square, for modeling interaction effects, i.e., the quadratic terms in our algorithm [29]. Based on a recommendation of Aiken and West [2], we standardized the IVs to create quadratic terms to facilitate result interpretation and to avoid the threat of multi-collinearity ${ }^{3}$. Results (Table 6) reveal consistent behavioral patterns between the two time points. In particular, results from T1 and T2

\footnotetext{
${ }^{3}$ The VIF values for all terms entered in HRA were lower than five, suggesting no threat of multi-collinearity (Hair et al., 1998).
} 
both suggest that: (1) although information quality and system quality had direct significant impacts on user satisfaction, Use did not; and (2) information quality and system quality, not Use, demonstrated quadratic effects on user satisfaction. These findings support $\mathrm{H} 2$ and $\mathrm{H} 3$, but not $\mathrm{H} 1$.

\begin{tabular}{|c|c|c|c|}
\hline \multicolumn{4}{|c|}{ Table 6. Hierarchical regression analysis: China mobile data (Study 1) } \\
\hline \multirow{3}{*}{ Independent variable } & \multicolumn{2}{|c|}{ Dependent variable: User satisfaction } & \\
\hline & TIME: T1 & TIME: T2 & \\
\hline & Standardized beta & Standardized beta & \\
\hline \multicolumn{4}{|l|}{ Step 1: Direct effect } \\
\hline Constant & 0.535 & 0.609 & \\
\hline Gender & n.s. & n.s. & \\
\hline Age & n.s. & n.s. & \\
\hline Education level & $-0.137 * *$ & n.s. & \\
\hline Prior usage experience & n.s. & n.s. & \\
\hline Service tenure & $-0.161 * *$ & $-0.136 * *$ & \\
\hline Information quality & $0.314 * *$ & $0.449 * *$ & \\
\hline System quality & $0.386 * *$ & $0.376 * *$ & \\
\hline Use & n.s. & n.s. & \\
\hline$\Delta \mathrm{R}^{2}$ for Step 1 & 0.404 & 0.491 & \\
\hline \multicolumn{4}{|l|}{ Step 2: Quadratic effect } \\
\hline$(\text { Use })^{2}$ & n.s. & n.s. & $\mathrm{H} 1(\mathrm{x})$ \\
\hline (Information quality) $^{2}$ & $-0.107 *$ & $-0.220 * *$ & $\mathrm{H} 2(\sqrt{ })$ \\
\hline$(\text { System quality })^{2}$ & $-0.124 *$ & $-0.104 *$ & $\mathrm{H} 3(\sqrt{ })$ \\
\hline$\Delta \mathrm{R}^{2}$ for Step 2 & 0.025 & 0.051 & \\
\hline Overall model $\mathrm{R}^{2}$ & 0.429 & 0.542 & \\
\hline$* *: \mathrm{p}<0.01 \quad *: \mathrm{p}<0.05$ & & & \\
\hline
\end{tabular}

Inclusion of the quadratic terms of information quality and system quality enhanced the explained variance from $40.4 \%$ to $42.9 \%$ (an increase of $2.5 \%$ in R-Square) for T1 and from $49.1 \%$ to $54.2 \%$ (an increase of 5.1\% in R-Square) for T2. Following Cohen [17] and Mathieson et al. [50], we calculated the effect size $f^{2}$ and evaluated the significance of the derived $f^{2}$ statistics using a pseudo $F$ test. ${ }^{4}$ The resulting $f^{2}$ of 0.044 at $\mathrm{T} 1$, with a p-value of 0.005 , represents a significant small-to-medium effect; the

\footnotetext{
${ }^{4}$ The effect size $f^{2}$ can be calculated as $\left(\mathrm{R}^{2}\right.$ full model - $\mathrm{R}^{2}$ partial model)/(1- $\mathrm{R}^{2}$ full model) [17]. Multiplying $f^{2}$ by (n-k-1), where $n$ equals sample size and $k$ equals the number of independent variables, offers a pseudo $F$ test for evaluating the significance of the $f^{2}$ statistic with 1 and n-k degree of freedom. According to Cohen [17], an effect size of 0.02, 0.15 , and 0.35 is small, medium, and large, respectively.
} 
resulting $f^{2}$ of 0.111 at $\mathrm{T} 2$, with a $\mathrm{p}$-value of 0.000 , also represents a salient small-to-medium effect size $[17,50]$. Therefore, the evidence suggests that adding quadratic items of information quality and system quality significantly increases explanatory power of the model.

\section{Reflection on Study 1}

A reflection on Study 1 reveals two issues worthy of further investigation. First, the non-significant influence of use on satisfaction may be a result of the non-voluntary nature of SIS. Voluntariness refers to the extent to which users perceive system use as non-mandatory $[55,89]$. Voluntariness is, in essence, about whether an individual perceives that another social actor (boss, colleague, friend, family) wants him/her to perform a specific behavior (such as adopting a technology), and the social actor has the ability to reward behavior and punish non-behavior [90, 95]. In Study 1, the use of the SIS system was largely mandatory; CSRs were required to use the SIS system. This mandatory nature of system use makes the marginal utility of use irrelevant because system use in this case is the consequence of organizational/managerial mandate rather than driven by the real benefits one obtains from use [67]. In summary, in mandatory use contexts, the user likely derives utility primarily from consumption of the attributes (i.e., information quality and system quality) of the system.

Second, the cost issue was not included in Study 1. System use is accompanied by cost. At the individual level, such costs can be the time and effort required to use an IS. Costs can influence how

people use an IS or switch to a new IS [61]. Study 1 did not yield an ideal context for studying cost issues associated with learning and using the system because the SIS system was implemented for 16 months and was being routinely operated. Therefore, our subjects would have likely passed the learning curve where the effects of costs would be more obvious.

Therefore, we conducted another study under a different content to further examine the potential influence of voluntariness and cost. 


\subsection{Study Two: Student use of PBwiki}

The second study investigated voluntary use of students of a wiki system called PBwiki. Wiki systems are considered an ideal platform for teaching and research [42]. PBwiki is a popular online wiki system that facilitates student collaborations by allowing students to work on the same Web pages with a record of all previous revisions.

Study 2 supplements Study 1 in two ways. First, it is under a voluntary-use context. Students in our sample, to a large degree, determined whether they would use PBwiki. Second, PBwiki was relatively less well-known such that most, if not all students, did not have prior experience with the program, thus providing an ideal context for us to study cost issues associated with learning how to use the wiki system. The IS Success Model does not include a cost factor explicitly.

In this research, we propose to focus on one particular cost, that is, perceived cognitive effort (PCE), which refers to the cognitive effort that a person perceives as required to learn or use a technology [94]. PCE has proven to influence how people use ISs such as e-commerce Web sites [94]. In line with economic theories, both benefit factors, such as information quality, system quality, and system Use, and cost factor (PCE) are believed to influence satisfaction simultaneously. A person needs to spend cognitive resources to learn how to use an IS. Such cognitive resources may lower user satisfaction with the IS, which is reflected as a negative relationship between PCE and satisfaction. However, such negative influence may diminish when the required cognitive resources increase. The rationale is that after the initial investment of cognitive resources in learning the technology, people becomes familiar with the technology, thus an equal amount of cognitive resources can lead to less satisfaction decrease.

We conducted the study in a university in Hong Kong. We studied the students of a master-level class that used PBwiki for information exchange. The survey included all 98 students in the class. Data were collected at the end of the three-month class. The survey instruments, which contained questions about the IVs, the DV, and the demographics, were administered to all students. We collected 84 complete responses. Table 7 presents the profiles of these students. 


\section{Measures}

The measures for information quality, system quality, and user satisfaction are consistent with those in Study 1. The instrument was first pre-tested on 10 students in another MBA class. Minor modifications were then made based on their feedback. The use of PBwiki was largely voluntary in this study; thus the measures of Davis et al. (1993) were adapted to measure system use. Measures for perceived cognitive effort were adapted from Wang and Benbasat's [94] research. Similar to Study 1, we included control variables such as gender, education, age, and service tenure (in months).

\begin{tabular}{|c|c|c|}
\hline \multicolumn{3}{|c|}{ Table 7. Sample demographics of Study 2 } \\
\hline \multirow{2}{*}{ Gender } & Category & Percentage \\
\hline \multirow{2}{*}{ Age } & Male & $54 \%$ \\
\cline { 2 - 3 } & Female & $46 \%$ \\
\hline & 18 years to 30 years old & $52 \%$ \\
\cline { 2 - 3 } & 31 years to 40 years old & $48 \%$ \\
\hline Prior PBwiki experience (Months) & Mean & Std. deviation \\
\hline Computer experience (Years) & 0.46 & 0.72 \\
\hline
\end{tabular}

\section{Measurement Model}

Principal factor analysis was performed to assess the properties of the multi-item constructs (information quality and system quality). In terms of reliability, the values of Cronbach's alpha and composite reliability were all greater than 0.707 (Table 8) [57]. The average variance extracted (AVE) statistic for each construct was higher than the suggested threshold of 0.50 [25]. Table 9 reveals that each item loaded high (all $>0.707)$ on its corresponding construct and much lower on the other constructs $(<0.40)$. The square root of AVE of every construct was higher than its correlations with other constructs, indicating discriminant validity [25]. For common method bias (CMB), we executed actions similar to those in Study 1 and found no serious concerns. The aforementioned pieces of evidences suggest appropriate measurements. 


\begin{tabular}{|l|c|c|c|c|c|c|c|c|c|c|}
\hline \multicolumn{1}{|c|}{ Table 8. Descriptive, internal consistency, convergent, and discriminant validity (Study 2) } \\
\hline Constructs & Mean & $\begin{array}{c}\text { Standard } \\
\text { Deviation }\end{array}$ & $\begin{array}{c}\text { Cronbach's } \\
\text { alpha }\end{array}$ & $\begin{array}{c}\text { Composite } \\
\text { reliability }\end{array}$ & AVE & $\mathbf{1}$ & $\mathbf{2}$ & $\mathbf{3}$ & $\mathbf{4}$ & $\mathbf{5}$ \\
\hline 1. Information quality & 5.48 & 0.91 & 0.90 & 0.90 & 0.75 & $\mathbf{0 . 8 6}(\mathbf{a})$ & & & & \\
\hline 2. System quality & 5.85 & 0.72 & 0.91 & 0.91 & 0.76 & $0.26(\mathrm{~b})$ & $\mathbf{0 . 8 7}$ & & & \\
\hline 3. Use (d) & 0.75 & 0.12 & N.A. & N.A. & N.A. & 0.56 & 0.41 & N.A. & & \\
\hline 4. User satisfaction (d) & 5.60 & 0.69 & N.A. & N.A. & N.A. & 0.58 & 0.61 & 0.66 & N.A. & \\
\hline 5. PCE & 2.47 & 0.77 & 0.80 & 0.81 & 0.60 & -0.50 & -0.39 & -0.56 & -0.45 & $\mathbf{0 . 7 7}$ \\
\hline $\begin{array}{l}\text { a. Diagonals represent the square root of the AVE. } \\
\text { b. Off diagonal elements are the correlations among constructs. } \\
\text { c. For discriminant validity, diagonal elements should be larger than off-diagonal elements. } \\
\text { d. A single-item measure was used. }\end{array}$ \\
\hline
\end{tabular}

\begin{tabular}{|c|c|c|c|c|}
\hline \multicolumn{5}{|c|}{ Table 9. Item loadings and Cross loadings (Study 2) } \\
\hline \multirow{2}{*}{ Construct } & \multirow{2}{*}{ Items } & $\mathbf{1}$ & $\mathbf{2}$ & $\mathbf{3}$ \\
\cline { 2 - 5 } & & 0.961 & -0.106 & 0.055 \\
\hline \multirow{3}{*}{ 1. information quality } & InfoQ1 & 0.886 & 0.199 & -0.110 \\
\cline { 2 - 5 } & InfoQ2 & 0.728 & 0.128 & 0.231 \\
\cline { 2 - 5 } & InfoQ3 & 0.024 & 0.926 & -0.030 \\
\hline \multirow{3}{*}{ 2. system quality } & SysQ1 & 0.075 & 0.870 & 0.031 \\
\cline { 2 - 5 } & SysQ 2 & -0.025 & 0.823 & 0.256 \\
\cline { 2 - 5 } & SysQ 3 & 0.069 & -0.164 & 0.866 \\
\hline \multirow{3}{*}{3. PCE } & PCE1 & -0.198 & 0.177 & 0.733 \\
\cline { 2 - 5 } & PCE2 & -0.041 & -0.211 & 0.706 \\
\cline { 2 - 5 } & PCE3 & & & \\
\hline
\end{tabular}

\section{Structural Model}

Similar to Study 1, we used HRA for hypothesis testing. The results (Table 10) suggest that: (1) Use, information quality, and system quality all have direct significant influence on satisfaction; and (2) both Use and system quality demonstrate quadratic effects on satisfaction, whereas information quality does not (thus supporting $\mathrm{H} 1$ and $\mathrm{H} 3$, but not $\mathrm{H} 2$ ).

By including the quadratic effect, we increased the explained variance from $61.1 \%$ to $68.6 \%$ (an increase of $7.5 \%$ in R-Square). The resulting $f^{2}$ of 0.239 , with a p-value smaller than 0.001 , represents a 
salient medium-to-large effect size. The aforementioned pieces of evidence collectively suggest that the addition of quadratic effects of system use substantially increases the explanatory power of the model.

\begin{tabular}{|c|c|c|}
\hline \multicolumn{3}{|c|}{ Table 10. Hierarchical regression analysis: PBwiki (Study 2) } \\
\hline \multirow{2}{*}{ Independent variable } & Dependent variable: User satisfaction & \\
\hline & Standardized beta & \\
\hline \multicolumn{3}{|l|}{ Step 1: Direct effect } \\
\hline Constant & 2.497 & \\
\hline Gender & n.s. & \\
\hline Age & n.s. & \\
\hline Computer experience & n.s. & \\
\hline Prior usage experience & $0.148 *$ & \\
\hline PCE & $-0.212 *$ & \\
\hline Use & $0.434 * *$ & \\
\hline Information quality & $0.264 *$ & \\
\hline System quality & $0.320 *$ & \\
\hline$\Delta \mathrm{R}^{2}$ for Step 1 & $61.1 \%$ & \\
\hline \multicolumn{3}{|l|}{ Step 2: Quadratic effect } \\
\hline$(\mathrm{PCE})^{2}$ & n.s. & \\
\hline$(\text { Use })^{2}$ & $-0.145 *$ & $\mathrm{H} 1(\sqrt{ })$ \\
\hline${\text { (Information quality })^{2}}^{2}$ & n.s. & $\mathrm{H} 2(\mathrm{x})$ \\
\hline$(\text { System quality })^{2}$ & $-0.138 *$ & $\mathrm{H} 3(\sqrt{ })$ \\
\hline$\Delta \mathrm{R}^{2}$ for Step 2 & $7.5 \%$ & \\
\hline Overall model $\mathrm{R}^{2}$ & $68.6 \%$ & \\
\hline$* *: \mathrm{p}<0.01 \quad *: \mathrm{p}<0.05$ & & \\
\hline
\end{tabular}

\section{Mediation Analysis}

Following DeLone and McLean $[19,20]$ our assumption is that information quality and system quality affect Use, which in turn, affects user satisfaction. In other words, prior research also suggests that Use may somewhat mediate the influence of information quality and system quality on satisfaction. Thus, we conducted a mediation test, following the three-step procedure suggested by Baron and Kenny [7]. Specifically, we first tested the direct impacts of information quality and system quality on satisfaction. Then, the direct effect of Use on satisfaction was tested. Finally, we included information quality, system 
quality, and Use in one model as three antecedents of satisfaction and examined whether the direct impact of information quality and system quality decreases when Use is included. The results, which are summarized in Table 11, suggest that Use partially mediates the direct effects of information quality and system quality, as well as the quadratic effect of system quality. ${ }^{5}$

\begin{tabular}{|c|c|c|c|}
\hline \multicolumn{4}{|c|}{ Table 11. Mediation analysis (Study 2) } \\
\hline & Model 1 & Model 2 & Model 3 \\
\hline Constant & 3.490 & 4.187 & 2.497 \\
\hline Gender & n.s. & n.s. & n.s. \\
\hline Age & n.s. & n.s. & n.s. \\
\hline Computer experience & n.s. & n.s. & n.s. \\
\hline Prior usage experience & n.s. & $0.158 *$ & $0.148 *$ \\
\hline PCE & $-0.194 *$ & $-0.243 *$ & $-0.212 *$ \\
\hline Information quality & $0.367 * *$ & & $0.264 *$ \\
\hline System quality & $0.341 *$ & & $0.320 *$ \\
\hline (Information quality) $^{2}$ & n.s. & & n.s. \\
\hline$(\text { System quality })^{2}$ & $-0.141 *$ & & $-0.138 *$ \\
\hline$(\mathrm{PCE})^{2}$ & n.s. & n.s. & n.s. \\
\hline Use & & $0.523 * *$ & $0.434 * *$ \\
\hline$(\text { Use })^{2}$ & & $-0.128 *$ & $-0.145 *$ \\
\hline Overall model $\mathrm{R}^{2}$ & $65.4 \%$ & $61.6 \%$ & $68.6 \%$ \\
\hline$* *: \mathrm{p}<0.01 \quad *: \mathrm{p}<0.05$ & & & \\
\hline
\end{tabular}

\section{Discussion}

\subsection{Major Findings and Research Implications}

This research confirms the importance of studying theory-driven non-linear effects of system use, information quality, and system quality on user satisfaction. Prior research on user satisfaction, rooted strongly in psychological Information Integration Theory, examined how user evaluations of various

\footnotetext{
${ }^{5}$ We did not conduct the mediation test in Study 1 because use has no impact on user satisfaction. As such, we could conclude that no mediation effect was detected.
} 
aspects of an information system may be integrated in a linear or non-linear manner to form user satisfaction with this system. This study extends this research stream by drawing on economic theories to investigate how changes in system use and user perceptions affect user satisfaction. In addition, the application of economic theories enables the study of the non-linear impact of system use on user satisfaction, which would not be possible if IIT was employed.

When re-conceptualizing user satisfaction as a proxy of utility, we noticed that use satisfaction is not completely identical to utility. Utility is a direct result of consumption and is about consumers' happiness. User satisfaction, on the other hand, is more remotely related to consumption. Factors other than consumption, e.g., disconfirmation may influence user satisfaction too [11].

Findings from our two empirical studies in the context of SIS and wiki technology confirm the consumptive nature of IS use. In other words, technology users can also be conceived as consumers [44]. As expected, we observed the expected quadratic effects of system use and information quality/system quality on user satisfaction. The addition of quadratic items significantly increased the explanatory power of the research model in both studies. In the first study, unlike information quality/system quality, system use did not demonstrate significant quadratic effects. We attributed this result to the mandatory context of system use in the first study. Accordingly, we conducted the second study on student use of the PBwiki, which was largely voluntary. We observed the expected diminishing influence of increased system use on user satisfaction, demonstrating the law of diminishing marginal utility. Findings from the two studies jointly suggest that the law of diminishing marginal utility does not hold for system use in mandatory contexts.

An interesting finding on the relationship between PCE and user satisfaction was discovered in Study 2. On the one hand, PCE has a significant negative effect on satisfaction, as expected. On the other hand, we do not find any diminishing effects of PCE on satisfaction. This finding may be a result of the simplicity of PBwiki. PBwiki is a simple innovation, and the Master students may not experience any difficulty in learning how to use it. 
It is worth noting that the original IS Success model does not include PCE. We consider it necessary to add PCE to the IS Success Model in light of the fact that using a technology comes with necessary costs. This is also consistent with Utility Maximization, which essentially concerns how to maximize the utility within budget constraints (e.g., costs). Adding cost (i.e., PCE) to the IS success model explicitly incorporates the costs associated with using the system.

In addition, we have assumed that more use leads to high satisfaction. This assumption may not always be true. On the one hand, more use may be a result of system deficiencies [52]. The user has to spend more time bypassing system limitations. In this case, more system use indicates the deficiencies of the system. On the other hand, consumption of goods or services can be satiated. In other words, the marginal utility of goods or services can be zero or negative after a threshold. The same is true for information systems. The marginal utility of system use is diminishing, and upon one point (the satiation point), marginal utility becomes zero or even negative. This is a promising topic for future research.

Beyond an enriched understanding of the formation of user satisfaction, a broader implication of this research is the application of economic theories to study user behaviors. Inspired by this research, we encourage IS scholars to further exploit the rich sources of theories in economics and to explicitly lay out and discuss connections between economics and user studies in IS research ${ }^{6}$. The application of economic theories is not new in IS research. These theories have been widely applied in the study of IT investments at the organizational level [e.g., 8]. However, economic theories are rarely applied in studying individual user behavior [99]. Economics has long been interested in resource-constrained human behaviors and share many similarities with user behavior research in terms of subject matter and level of analysis. The movements of behavioral economics $[40,72,79,87]$ and information economics $[3$, $73,77]$, which investigate the implications of bound rationality and self-interest of human beings and the impact of information asymmetry on decision-making, can significantly contribute to IS research by treating IS users as "social actors" [45]. This research demonstrates that in order to apply economic

\footnotetext{
${ }^{6}$ Although we attempted to connect economics and user studies in IS research, we do not purport to offer a contribution to economics literature.
} 
theories to IS research, the assumptions held in economics need to be examined and released with great caution.

Methodologically, we applied quadratic terms and HRA to empirically examine the non-linear relationship between user perceptions of IS attributes and user satisfaction. Although using quadratic terms is a popular technique for modeling non-linear relationships in other disciplines $[22,47,58]$, such function is underused in the IS field. A number of recent IS studies have employed polynomial regression for testing theories of confirmation-disconfirmation $[14,91]$, thus our application of quadratic terms and HRA is consistent with our choice of utility theories.

\subsection{A Reflection on the New Approach}

Thus far, we have developed a new utility-based approach that emphasizes the non-linear nature of relationships among user satisfaction, system use, and information quality/system quality. Figure 2 illustrates the differences between this approach and the existing IIT approach.

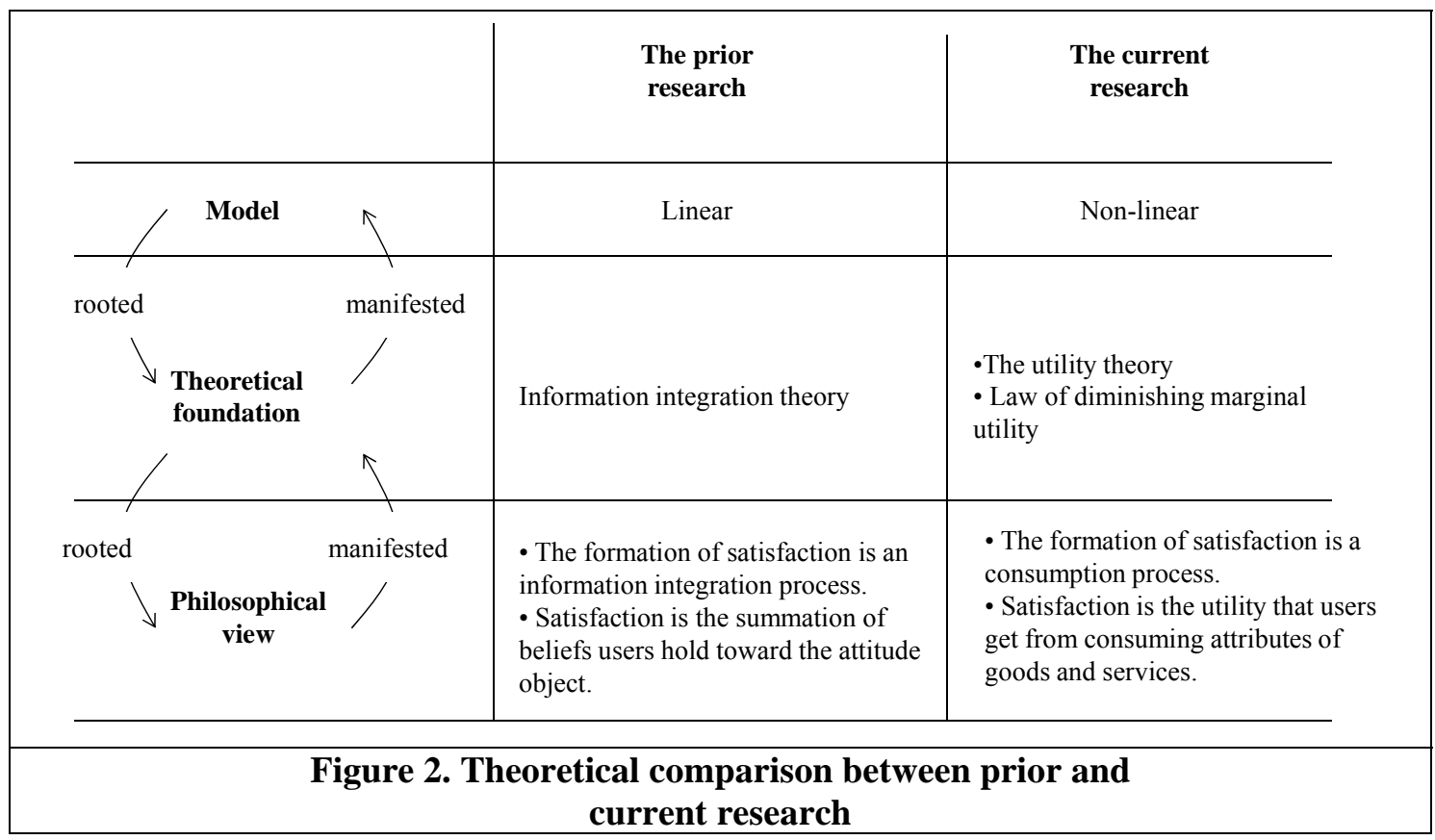


The fundamental difference between prior and current research lies in their theoretical assumptions. IIT conceptualizes satisfaction as the weighted summation of the perceptions of various attributes. By contrast, the utility approach views user satisfaction as a utility gained by consuming IS. The impact of system use and IS attributes on user satisfaction is analogous to the consumption of goods that generates consumer utility. This perspective is relevant in theorizing the diminishing marginal impact of system use and information quality/system quality on user satisfaction. The IIT and the utility approaches complement each other well (Appendix B). The IIT approach focuses on various strategies of valuating and integrating currently available perceptions in developing user satisfaction at any given moment, whereas the utility approach addresses how user satisfaction responds to changes in system use and user perceptions.

It is worth noting that when applying economic theories to IS researchers, it is necessary to examine the assumptions that are often held in economics. For example, as discussed earlier, economics has assumed that individuals follow the utility function, which is apparently arguable. When applying utility theory to study user satisfaction, we released several assumptions. Future research should carefully examine the assumptions in the economic theory.

\subsection{Limitations}

First, the sample size of the second study is small. Although we tested for robustness in analysis, a larger sample size is certainly preferable. The small sample size may account for the non-significant relationship we found in the empirical study due to its low statistical power. Also, using the student sample may limit how the results can be generalized to other contexts [18].

Second, the application of the law of diminishing marginal utility implies that all IS studied should be taken as "normal goods" [30]. This assumption can be challenged. For example, people may become addicted to gaming technologies where the law of diminishing marginal utility may be inapplicable. In addition, in uncertain conditions and without sufficient information, people may select "lemons" (that is, products with deficiencies) [3]. Similarly, people may accept a lemon system (such as a system that lacks 
the ability to meet an individual's needs) [1]. Thus, future research can study "lemon" information systems. In such systems, more use may not increase satisfaction. As a result of direct experience, people know that the system will never meet their needs.

Third, this research to some degree overlooks individual differences. Although we control for individual difference factors, we assumed that individual users follow the same utility curve. This is implied in our strategy of using the quadratic regression equation (QRE) and then examining the estimates. This assumption, albeit commonly held in economic and marketing research [54], can be loosened in future research. One way to do so is to conduct paired sample analysis, i.e., to analyze the relationship between a person's evaluation of the information system and utility at different points of time.

Fourth, system use is measured by percentage of work time (Study 1) and frequency of use (Study 2). Indicating how much the user generally utilizes the system, neither of the measures is a direct indicator of the overall consumption of the system. An ideal measure would be the total amount of use of each individual extracted from the system $\log$ file.

\subsection{Practical Implications}

A major implication of this research is that the marginal utilities of system use and user evaluations may be decreasing. Our findings suggest that one should first calculate marginal utilities of system use and information quality/system quality and then invest in the attributes with the highest marginal utilities to enhance user satisfaction. In fact, the IIT approach and the utility approach may yield different conclusions with regard to which aspect of an IS, information quality, or system quality, should be invested (see Appendix $\mathrm{C}$ for a detailed demonstration). In short, the traditional linear model is inadequate compared with the non-linear model. User satisfaction researchers have been using linear models as an effective proxy for non-linear relationships [70]; however, the linear model does not allow integration of diminishing marginal utility. Our study demonstrates that marginal utility should be a major consideration when making resource-allocation decisions with regard to IS improvements. Therefore, we 
believe that the non-linear model serves as a superior decision-making tool for practitioners. Specifically, our model allows practitioners to make better decisions on choosing optimal information quality level, system quality level, and system usage level, according to the desired satisfaction as illustrated in Appendix C. 


\section{References}

[1] Abrahamson, E. Managerial Fads and Fashions: The Diffusion and Rejection of Innovations. The Academy of Management Review, 16, 3 (1991) 586-612.

[2] Aiken, L.S., and West, S.G. Multiple Regression: Testing and Interpreting Interactions. Newbury Park, CA: Sage, 1991.

[3] Akerlof, G. The Market for 'Lemons': Quality Uncertainty and the Market Mechanism. Quarterly Journal of Economics, 84, 3 (1970) 488-500.

[4] Anderson, N.H. Foundations of Information Integration. New York, NY: Academic Press, 1981.

[5] Arrow, K.J. Essays in the Theory of Risk-Bearing. Chicago: Markham, 1971.

[6] Bailey, J.E., and Pearson, S.W. Development of a tool for measuring and analysing computer user satisfaction. Management Science, 29, 5 (1983) 530-545.

[7] Baron, R.M., and Kenny, D. The moderator-mediator variable distinction in social psychological research: Conceptual, strategic , and statistical considerations. Journal of Personality and Social Psychology, 51, 6 (1986) 1173-1182.

[8] Baskerville, R.L., and Myers, M.D. Information systems as a reference discipline. MIS Quarterly, 26, 1 (2002) 1-14.

[9] Bateman, I.; Munro, A.; Rhodes, B.; Starmer, C.; and Sugden, R. A Test of the Theory of ReferenceDependent Preferences. Quarterly Journal of Economics, 112, 2 (1997) 479-505.

[10] Bentham, J. An Introduction to the Principle of Morals and Legislations. Oxford, UK: Blackwell, 1789.

[11] Bhattacherjee, A. Understanding information systems continuance: An expectation-confirmation model. MIS Quarterly, 25, 3 (2001) 351-370.

[12] Brislin, R.W.; Lonner, W.J.; and Thorndike, R.M. Cross-Cultural Research Methods. New York: Wiley, 1973.

[13] Brown, S.A.; Massey, A.P.; Montoyaweiss, M.M.; and Burkman, J.R. Do I really have to ? User acceptance of mandated technology. European Journal Information Systems, 11, 4 (2002) 283-295.

[14] Brown, S.A.; Venkatesh, V.; Kuruzovich, J.; and Massey, A.P. Expectation confirmation: An examination of three competing models. Organizational Behavior and Human Decision Processes, $105,(2008)$ 52-66.

[15] Carter, S., and McBride, M. Experienced utility versus decision utility: Putting the ' $S$ ' in satisfaction. The Journal of Socio-Economics, 42, (2013) 13-23.

[16] Chan, F.K.Y.; Thong, J.Y.L.; Venkatesh, V.; Brown, S.A.; Hu, P.J.-H.; and Tam, K.Y. Modeling Citizen Satisfaction with Mandatory Adoption of an E-Government Technology. Journal of the Association for Information Systems, 11, 10 (2010) 519-549.

[17] Cohen, J. Statistical Power Analysis for the Behavioral Sciences. HillsDale, NJ: Lawrence Erlbaum, 1988.

[18] Compeau, D.; Marcolin, B.; Kelley, H.; and Higgins, C. Generalizability of Information Systems Research Using Student Subjects: A Reflection on Our Practices and Recommendations for Future Research. Information Systems Research, (forthcoming)

[19] DeLone, W.H., and McLean, E.R. Information systems success: The quest for the dependent variable. Information Systems Research, 3, (1992) 60-95.

[20] DeLone, W.H., and McLean, E.R. The DeLone and McLean model of information systems success: A ten-year update. Journal of Management Information Systems, 19, 4 (2003) 9-30.

[21] Edgeworth, F.Y. Mathematical Psychics. London: C. K. Paul, 1881.

[22] Edwards, J. The study of congruence in organizational behavior research: Critique and a proposed alternative. Organizational Behavior and Human Decision Processes, 58, 1 (1994) 51-100.

[23] Ferraro, F.; Pfeffer, J.; and Sutton, R. Economics language and assumptions: How theories can become self-fulfilling. Academy of Management Review, 30, 1 (2005) 8-24.

[24] Fishbein, M., and Ajzen, I. Beliefs, attitude, intention and behavior: An introduction to theory and research. Reading, MA: Addison-Wesley, 1975.

[25] Fornell, C., and Larcker, D.F. Evaluating structural equation models with unobservable variables and 
measurement error. Journal of Marketing Research, 18, 1 (1981) 39.

[26] Friedman, M., and Savage, L.J. The Utility Analysis of Choices Involving Risks. Journal of Political Economy, 56, (1948) 279-304.

[27] Gati, I., and Tversky, A. Weighting common and distinctive features in perceptual and conceptual judgments. Cognitive Psychology, 16, (1984) 341-370.

[28] Gatignon, H., and Robertson, T.S. The impact of risk and competition on choice of innovations. Marketing Letters, 4, 3 (1993) 191-204.

[29] Goodhue, D.; Lewis, W.; and Thompson, R. Statistical power in analyzing interaction effects: Questioning the advantage of PLS with product indicators. Information Systems Research, 18, 2 (2007) 211-227.

[30] Green, H.A.J. Direct Additivity and Consumers' Behaviour. Oxford Economic Papers, 13, 132-136 (1961)

[31] Greene, J., and Baron, J. Intuitions about declining marginal utility. JOURNAL OF BEHAVIORAL DECISION MAKING, 14, (2001) 243-255.

[32] Hartwick, J., and Barki, H. Explaining the Role of User Participation in Information System Use. Management Science, 40, 4 (1994) 440-465.

[33] Hausknecht, D.R. Measurement Scales in Consumer Satisfaction/Dissatisfaction. Journal of Satisfaction, Dissatisfaction and Complaint Behavior, 3 (1990) 1-11.

[34] Homburg, C.; Koschate, N.; and Hoyer, W.D. Do Satisfied Customers Really Pay More? A Study of the Relationship Between Customer Satisfaction and Willingness to Pay. Journal of Marketing, 69, 2 (2005) 84-96.

[35] Hsieh, J.P.A.; Rai, A.; Petter, S.; and Zhang, T. Impact of User Satisfaction with Mandated CRM Use on Employee Service Quality. MIS Quarterly, 36, 4 (2012) 1065-1080.

[36] Iivari, J. An empirical test of the DeLone-McLean model of information system success. The DATA BASE for Advances in Information Systems, 36, 2 (2005) 8 - 27.

[37] Ives, B.; Olson, M.H.; and Baroudi, J.J. The measurement of user information satisfaction. COMMUNICATIONS OF THE ACM, 26, 10 (1983) 785-793.

[38] Jasperson, J.S.; Carter, P.E.; and Zmud, R.W. A comprehensive conceptualization of the postadoptive behaviors associated with IT-enabled work systems. MIS Quarterly, 29, 3 (2005) 525-557.

[39] Jevons, W.S. The Theory of Political Economy. 1st ed., London and New York: MacMillan and Co, 1879.

[40] Kahneman, D., and Tversky, A. Prospect Theory: An Analysis of Decisions Under Risk. Econometrica, 47, (1979) 263-91.

[41] Kahneman, D.; Wakker, P.P.; and Sarin, R. Back to Bentham? Explorations of Experienced Utility. Quarterly Journal of Economics, 112, 2 (1997) 375-405.

[42] Kane, G.C., and Fichman, R.G. The showmaker's children: Using wikis for information systems teaching, research, and publication. MIS Quarterly, 33, 1 (2009) 1-22.

[43] Keeney, R.L., and Raiffa, H. Decisions with Multiple Objectives: Preferences and Value Tradeoffs. New York: Wiley, 1976.

[44] Kim, H.-W.; Chan, H.C.; and Gupta, S. Value-based Adoption of Mobile Internet: An empirical investigation. Decision Support Systems, 43, 1 (2007) 111-126.

[45] Lamb, R., and Kling, R. Reconceptualizing users as social actors in information systems research. MIS Quarterly, 27, 2 (2003) 197-235.

[46] Limayem, M.; Hirt, S.G.; and Cheung, C.M.K. How Habit Limits the Predictive Power of Intention: The Case of Information Systems Continuance. MIS Quarterly, 31, 4 (2008) 705-737.

[47] Lu, J.W., and Beamish, P.W. International diversification and firm performance: The S-curve hypothesis. Academy of Management Journal, 47, 4 (2004) 598-609.

[48] Malhotra, N.K., and Mukherjee, A. The Relative Influence of Organizational Commitment and Job Satisfaction on Service Quality of Customer Contact Employees in Banking Call Centers. Journal of Service Marketing, 18, 2/3 (2004) 162-174.

[49] Marshall, A. Principles of Economics. 1890. 
[50] Mathieson, K.; Peacock, E.; and Chin, W.W. Extending the technology acceptance model: The influence of perceived user resources. Database for Advances in Information Systems, 32, 3 (2001) 86.

[51] McCalla, R.; Ezingeard, J.N.; and Money, K. A Behavioral Approach to CRM Systems Evaluation. Electronic Journal of Information Systems Evaluation, 6, 2 (2003) 145-154.

[52] McGill, T.J.; Hobbs, V.J.; and Klobas, J.E. User-developed applications and information systems success: a test of DeLone and McLean's model. Information Resources Management Journal, 16, 1 (2003) 24-45.

[53] Menger, C. Principles of Economics. 1871.

[54] Mittal, V.; Ross, W.T.; and Baldsare, P.M. The asymmetric impact of negative and positive attributelevel performance on overall satisfaction and repurchase intentions. Journal of Marketing, 62, (1998) 33-47.

[55] Moore, G.C., and Izak, B. Development of an instrument to measure the perception of adopting an information technology innovation. Information Systems Research, 23, 3 (1991) 192-222.

[56] Nowlis, S.M., and Simonson, I. The effect of new product features on brand choice. Journal of Marketing Research, XXXIII, (1996) 36-46.

[57] Nunnally, J.C., and Bernstein, I.H. Psychometric Theory. 3rd ed., New York: McGraw-Hill, 1994.

[58] Oh, W., and Pinsonneault, A. On the assessment of the strategic value of information technologies: Conceptual and analytical approaches. MIS Quarterly, 31, 2 (2007) 239-265.

[59] Oliver, R.L., and Bearden, W.O. The Role of Involvement in Satisfaction Process, in R.P. Bagozzi and A.M. Tybout, ed., Advances in Consumer Research, Ann Arbor, MI: Association for Consumer Research, 1983, 250-255.

[60] Podsakoff, P.; MacKenzie, S.; Lee, J.; and Podsakoff, N. Common method biases in behavioral research: A critical review of the literature and recommended remedies. JOURNAL OF APPLIED PSYCHOLOGY, 88, 5 (2003) 879-903.

[61] Polites, G.L., and Karahanna, E. Shackled to the Status Quo: The Inhibiting Effects of Incumbent System Habit, Switching Costs, and Inertia on New System Acceptance. MIS Quarterly, 36, 1 (2012) 21-42.

[62] Pratt, J.W. Risk Aversion in the Small and in the Large. Econometrica, 32, 1/2 (1964) 122-136.

[63] Rai, A.; Lang, S.S.; and Welker, R.B. Assessing the validity of IS success models: An empirical test and theoretical analysis. Information Systems Research, 13, 1 (2002) 50-69.

[64] Ramsey, F.P. A contribution to the theory of taxation. The Economic Journal, 37, (1927) 47-61.

[65] Samuelson, P.A. Foundations of Economic Analysis. Harvard University Press, 1947.

[66] Savage, L.J. The Foundations of Statistics. New York: Wiley, 1954.

[67] Seddon, P.B. A respecification and extension of the DeLone and McLean model of IS success. Information Systems Research, 8, 3 (1997) 240-253.

[68] Seddon, P.B., and Kiew, M.Y. A partial test and development of the DeLone and McLean model of IS success, in Proceedings of the International Conference on Information Systems, Atlanta, GA, 1994, Association for Information Systems 99-110.

[69] Sergeant, A., and Frenkel, S. When Do Customer Contact Employees Satisfy Customers. Journal of Service Research, 3, 1 (2000) 18-34.

[70] Sethi, V., and King, R.C. Nonlinear and noncompensatory models in user information satisfaction measurement. Information Systems Research, 10, 1 (1999) 87-96.

[71] Sharma, R.; Yetton, P.; and Crawford, J. Estimating the Effect of Common Method Variance: The Method-Method Pair Technique with an Illustration from TAM Research. MIS Quarterly, 33, 3 (2009) 473-490.

[72] Simon, H.A. A Behavioral Model of Rational Choice, Models of Man, Social and Rational: Mathematical Essays on Rational Human Behavior in a Social Setting

New York: Wiley, 1957.

[73] Spence, M.A. Job Market Signaling. Quarterly Journal of Economics, 83, 3 (1973) 355-377.

[74] Srull, T.K., and Wyer, R.S. Person memory and judgment. Psychological Review, 96, 1 (1989) 58- 
83.

[75] Stigler, G. The development of utility theory I. The Journal of Political Economy, 58, 307-327 (1950)

[76] Stigler, G. The development of utility theory II. The Journal of Political Economy, 58, 373-396 (1950)

[77] Stiglitz, J. The Theory of Screening, Education and the Distribution of Income. American Economic Review, 65, 3 (1975) 283-300.

[78] Sun, H. Understanding User Revisions When Using Information System Features: Adaptive System Use and Triggers. MIS Quarterly, 36, 2 (2012) 453-478.

[79] Thaler, R.H. Toward a positive theory of consumer choice, in Daniel Kahneman and Amos Tversky, ed., Choices, Values, and Frames, New York: Cambridge University Press, 2000, 268-287.

[80] Thaler, R.H.; Tversky, A.; Kahneman, D.; and Schwartz, A. The Effect of Myopia and Loss Aversion on Risk Taking: An Experimental Test*. Quarterly Journal of Economics, 112, 2 (1997) 647-661.

[81] Thompson, R.L.; Smith, H.J.; and Iacovou, C.L. The link between reporting quality and performance in IS projects. Information \& Management, 44, (2007) 196-205.

[82] Torgerson, W.S. Theory and Methods of Scaling. New York: John Wiley \& Sons, 1958.

[83] Torkzadeh, G., and Doll, W.J. The development of a tool for measuring the perceived impact of information technology on work. OMEGA-INTERNATIONAL JOURNAL OF MANAGEMENT SCIENCE, 27, 3 (1999) 327-339.

[84] Torkzadeh, G.; Koufteros, X.; and Doll, W.J. Confirmatory factor analysis and factorial invariance of the impact of information technology instrument. Omega, 33, (2005) 107-118.

[85] Tversky, A., and Kahneman, D. Judgment under uncertainty: Heuristics and biases. SCIENCE COMMUNICATION, 185, 4157 (1974) 1124-1131.

[86] Tversky, A., and Kahneman, D. Loss aversion in riskless choice: A reference-dependent model. Quarterly Journal of Economics, 106, 4 (1991) 1039-1061.

[87] Tversky, A., and Kahneman, D. Advances in prospect theory: Cumulative perspectivation of uncertainty. Journal of Risk and Uncertainty, 5 , 4 (1992) 297-323.

[88] Tyre, M.J., and Orlikowski, W.J. Windows of opportunity: Temporal patterns of technological adaptation in organizations. Organization Science, 5, 1 (1994) 98-118.

[89] Venkatesh, V., and Davis, F. A Theoretical Extension of the Technology Acceptance Model: Four Longitudinal Field Studies. Management Science, 46, 2 (2000) 186-204.

[90] Venkatesh, V., and Davis, F.D. A theoretical extension of the Technology Acceptance Model: Four longitudinal field studies. Management Science, 46, 2 (2000) 186-204.

[91] Venkatesh, V., and Goyal, S. Expectation disconfirmation and technology adoption: polynomial modeling and response surface analysis. MIS Quarterly, 34, 2 (2010) 281-303.

[92] Venkatesh, V.; Morris, M.G.; Davis, G.B.; and Davis, F.D. User acceptance of information technology: toward a unified view. MIS Quarterly, 27, 3 (2003) 425-478.

[93] von Neumann, J., and O.Morgenstern Theory of Games and Economic Behavior. Princeton: Princeton University Press, 1944.

[94] Wang, W., and Benbasat, I. Interactive Decision Aids for Consumer Decision Making in ECommerce: The Influence of Perceived Strategy Restrictiveness. MIS Quarterly, 33, 2 (2009)

[95] Warshaw, P.R. A new model for predicting behavioral intentions: An alternative to Fishbein. Journal of Marketing Research, 17, (1980) 153-172.

[96] Westbrook, R.A. A Rating Scale for Measuring Product/Service Satisfaction. Journal of Marketing, (1980) 68-72.

[97] Wixom, B.H., and Todd, P.A. A theoretical integration of user satisfaction and technology acceptance. Information Systems Research, 16, 1 (2005) 85-102.

[98] Wixom, B.H., and Watson, H.J. An empirical investigation of the factors affecting data warehousing success. MIS Quarterly, 25, 1 (2001) 17-41.

[99] Zhang, P.; Li, N.; Scialdone, M.J.; and Carey, J. The Intellectual Advancement of Human-Computer 
Interaction Research: A Critical Assessment of the MIS Literature (1990-2008). AIS Transactions on Human-Computer Interaction, 1, 3 (2009) 55-107. 


\section{Appendix A: The Instrument}

\section{Measurement Items for Study 1}

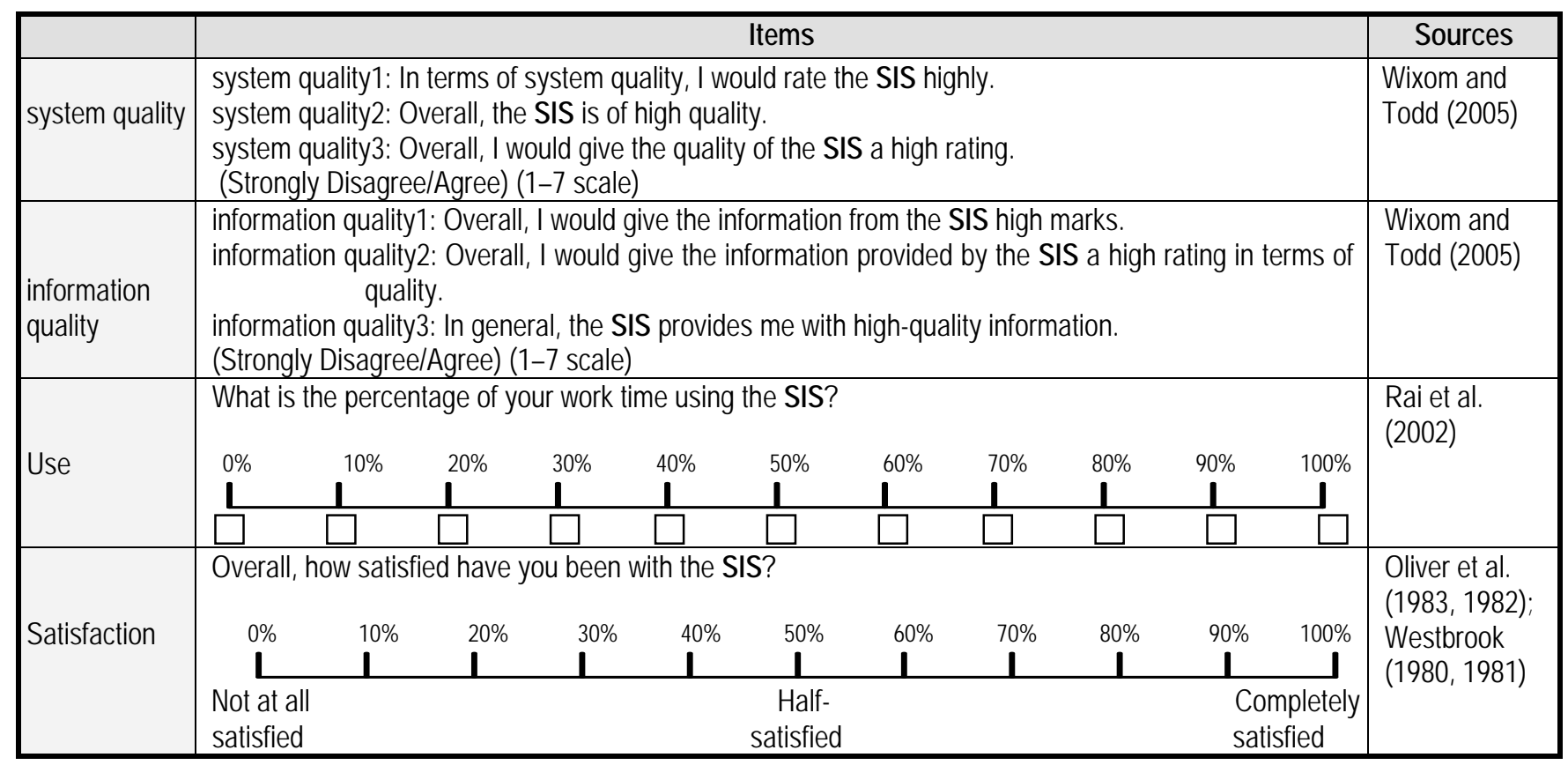

Measurement Items for Study 2

\begin{tabular}{|c|c|c|}
\hline Construct & Items & Sources \\
\hline system quality & $\begin{array}{l}\text { SysQ1: In terms of system quality, I would rate PBwiki highly. } \\
\text { SysQ 2: Overall, PBwiki is of high quality. } \\
\text { SysQ3: Overall, I would give the quality of PBwiki a high rating. } \\
\text { (Strongly Disagree/Agree) (1-7 scale) }\end{array}$ & $\begin{array}{l}\text { Wixom and } \\
\text { Todd (2005) }\end{array}$ \\
\hline $\begin{array}{l}\text { information } \\
\text { quality }\end{array}$ & $\begin{array}{l}\text { InfoQ1: Overall, I would give the information from PBwiki high marks. } \\
\text { InfoQ2: Overall, I would give the information provided by PBwiki a high rating in terms of quality. } \\
\text { InfoQ3: In general, PBwiki provides me with high-quality information. } \\
\text { (Strongly Disagree/Agree) (1-7 scale) }\end{array}$ & $\begin{array}{l}\text { Wixom and } \\
\text { Todd (2005) }\end{array}$ \\
\hline Use & $\begin{array}{l}\text { How frequently do you use PBwiki? } \\
\begin{array}{lllllll}\text { (1) Not at all, } \quad \text { (2) Less than once a week, (3) Once a week, } \\
\text { (4) Several times a week, (5) About once a day, or (6) Several times a day. }\end{array} \\
\text { (4) }\end{array}$ & $\begin{array}{l}\text { Davis et al. } \\
\text { (1993) }\end{array}$ \\
\hline Satisfaction & 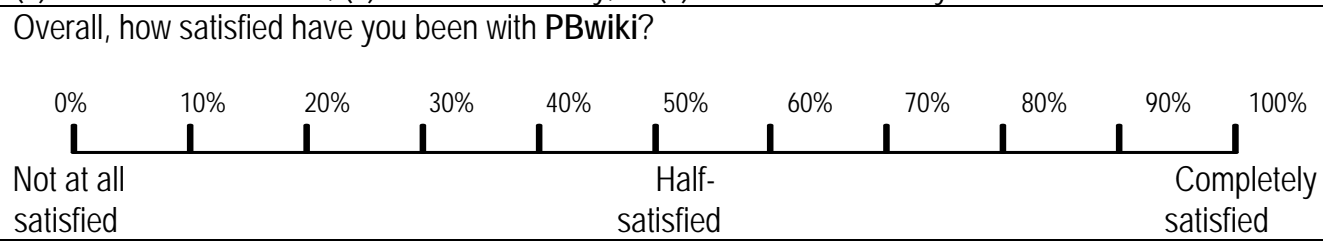 & $\begin{array}{l}\text { Oliver et al. } \\
(1983,1982) ; \\
\text { Westbrook } \\
(1980,1981)\end{array}$ \\
\hline PCE & $\begin{array}{l}\text { 1. The task of learning to use PBwiki takes too much time. } \\
\text { 2. Learning to use PBwiki requires too much effort. } \\
\text { 3. Learning to use PBwiki is too complex. }\end{array}$ & $\begin{array}{l}\text { Wang and } \\
\text { Benbasat [94] }\end{array}$ \\
\hline
\end{tabular}




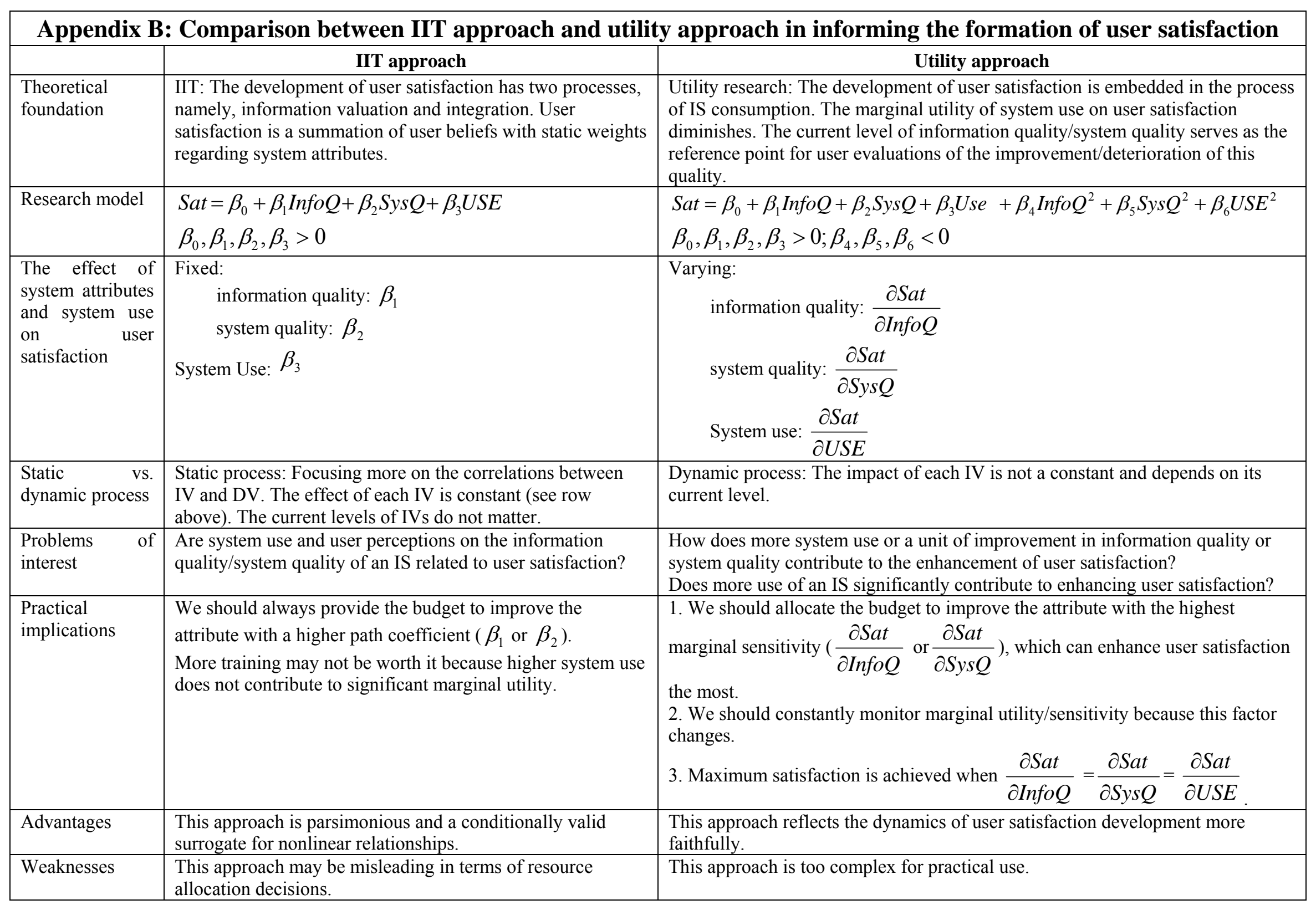




\section{Appendix C: An illustration of the different conclusions drawn from IIT and utility approaches.}

In Figure $\mathrm{C} 1$, we present two nonlinear utility curves, representing information quality and system quality, respectively, by drawing on utility theory. Both curves are concave, reflecting diminishing marginal utility. Points A and B represent future prospects of information quality and system quality, resulting from the same amount of investment. The dashed lines representing the linear relationship between perceptions of IS attributes and user satisfaction are drawn based on IIT; $\alpha$ and $\beta$ are path coefficients of information quality and system quality in the linear model, respectively. Following the linear model, we choose to invest in system quality because it has greater impact on satisfaction $(\beta>\alpha)$. However, based on the non-linear model, we should invest in information quality because it has greater marginal impact on user satisfaction (the slope tangent to the nonlinear model is steeper for information quality than for system quality).

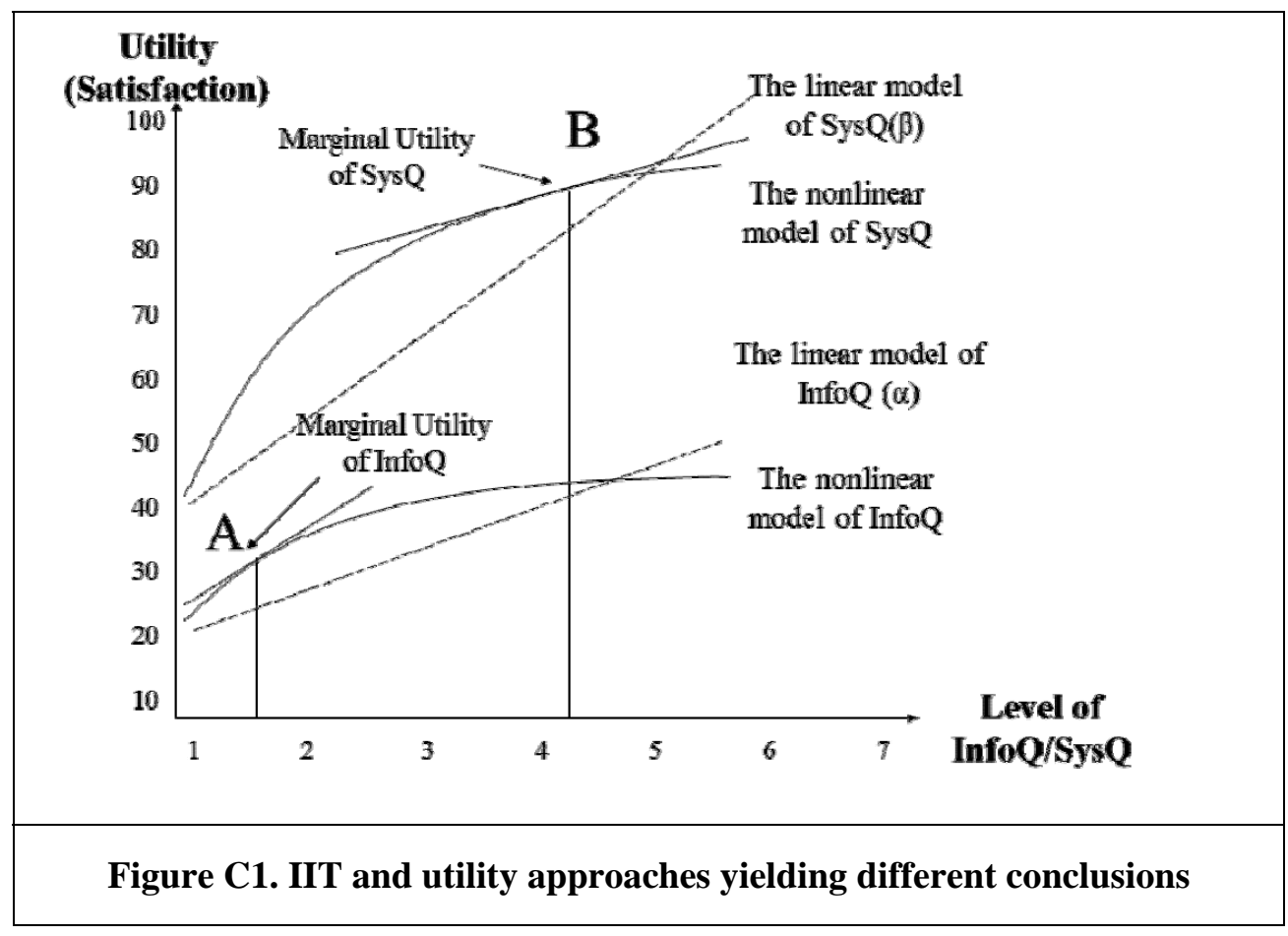

